Asian J. Med. Biol. Res. 2020, 6 (4), 628-634; doi: 10.3329/ajmbr.v6i4.51228

\author{
Asian Journal of \\ Medical and Biological Research \\ ISSN 2411-4472 (Print) 2412-5571 (Online) \\ www.ebupress.com/journal/ajmbr
}

\title{
Article \\ Nutritional status and dietary adequacy amid reproductive aged women in Cumilla, Bangladesh
}

\author{
Md. Hafizul Islam*, Ahmed Jubayer and Md. Moniruzzaman Nayan \\ Institute of Nutrition and Food Science, University of Dhaka, Dhaka-1000, Bangladesh \\ *Corresponding author: Md. Hafizul Islam, Institute of Nutrition and Food Science, University of Dhaka, \\ Dhaka-1000, Bangladesh. Phone: +8801728341778; E-mail: hafizinfs19@gmail.com
}

Received: 13 October 2020/Accepted: 16 November 2020/ Published: 31 December 2020

\begin{abstract}
Dietary patterns are evolving greatly during the last years and various diet and lifestyle related diseases are increasing day by day. The prevalence of double burden of malnutrition and various nutritional deficiency diseases among the reproductive aged women, the most vulnerable group has become a severe concern during the last decades. Therefore, the study focused on the nutritional status of reproductive aged women, their dietary food and nutrient intake and the adequacy of these consumed nutrients as compared to their requirements. A cross-sectional study was conducted among the randomly selected 355 households in Cumilla district in Bangladesh. The results showed that only about $32 \%$ of the participants were found having a normal BMI range. The percentage of underweight, overweight and obesity among the participants were $13.3 \%$ (95\% CI: 10.25, 16.36), 35.8\% (95\% CI: 31.49, 40.12) and 19.6\% (95\% CI: 16.04, 23.17) respectively. Dietary protein, carbohydrate, total fat consumption was $11.87 \%, 65.22 \%$ and $18.9 \%$ of energy. Consumption of vitamin A, C, D, Folic acid, calcium, sodium, riboflavin and potassium was very poor and found below EAR/AI among the most respondents. Thiamin, zinc, iron, phosphorous intake was satisfactory among the most respondents.
\end{abstract}

Keywords: reproductive aged women; nutritional status; dietary intake; nutritional adequacy; Cumilla

\section{Introduction}

Nutrition transition and epidemiologic transition in low- and middle-income countries have become significant topics in recent decades. The first one shows the trends in the change of diets from traditional foods to calorie dense, oily and processed foods (Drewnowski and Popkin, 2009). The later says the shift of diseases patterns from communicable to various non-communicable diseases (Miranda et al., 2008). Double burden of malnutrition has increased in recent years (Shafique et al., 2007; Biswas et al., 2017). According to BDHS 2014, the prevalence of underweight and overweight among the reproductive aged women in Bangladesh were $19 \%$ and 24\% respectively (Statistics and Mitra and Associates, 2013).This health problem is related with both their dietary quality, intake pattern and quantity. Underweight and overweight are not only problem themselves but also can generate other adverse health effect, pregnancy complications and non-communicable diseases (Sebire et al., 2001; Mamun et al., 2011; Chopra et al., 2013).

Nutritional consideration and improved diets are required during the reproductive aged women for maintaining a good health, recovering the menstrual losses and preparing for (Kaiser and Allen, 2002; Simpson et al., 2010, 2011)pregnancy. Micronutrients consumptions are still poor and various micronutrient deficiencies are prevailing (Nguyen et al., 2018). Although the situation has improved, some of these like iron deficiency anemia (IDA), iodine deficiency disorder (IDD), vitamin A deficiency disorder (VADD), folate, vitamin D, zinc, calcium, magnesium, phosphorous deficiencies are the main concern (Ahmed et al., 2016).

Female members of the families are the most vulnerable to poor dietary consumption as in most cases they have to eat after all the male members and children have eaten. They have to compromise any shortage of food and 
have to adopt all diet related coping strategies in case of food insecurity. Very few studies available in the literature that showed Nutritional status and dietary patterns of reproductive aged women in Bangladesh. Therefore, we focused on the nutritional status of reproductive aged women, their dietary patterns and adequacy of their nutrient intake as compared to recommended intake. This paper aims to fill the research gap, which in turn can help guide maternal nutrition and reproductive health program planners and policymakers to understand the condition of nutritional status and their dietary intake to assist in implementation of maternal nutrition and reproductive health program that will improve their health conditions and dietary nutrients intake.

\section{Methods and Materials}

\subsection{Study design, study area, sampling, materials}

This was a cross-sectional study conducted in the selected areas of Cumilla district in Bangladesh (about 100 kilometers south east of Dhaka) during the Month of April 2019. The selected areas included five villages namely Kalir Bazar, Gohinkhali, Jangalia, Ujirpur and Joypur. The households were randomly selected for the study and oral consent of the respondents were taken before the interview. Information from 355 households were collected for the study. Height scale, weighing scale were used for anthropometric measurements and structured questionnaire were used for collecting the required data. Socio-economic and demographic data, anthropometric information and dietary data were taken. Data were analyzed through Statistical Package for Social Sciences (SPSS version 25.0) (Nie et al., 1975).

\subsection{Anthropometric measurements and analysis}

Height and weight of the respondents were taken using the height scale, weighing scale. From this information body mass index (BMI) were calculated. This BMI values were then categorized using the BMI cut off value, BMI $<18.5 \mathrm{~kg} / \mathrm{m}^{2}$ as underweight, BMI 23 to $<27.5 \mathrm{~kg} / \mathrm{m}^{2}$ as overweight and $\mathrm{BMI} \geq 27.5 \mathrm{~kg} / \mathrm{m}^{2}$ as obese(Bmi and $\mathrm{Bmi}, 2004)$. Chi-square test was done to find the association of nutritional status with socio-economic characteristics.

\subsection{Dietary information and analysis}

Household 24-hour recall dietary intake information were collected. Raw weights of the food ingredients consumed during the previous 24 hours at the household were taken. For the convenience of accurate data collection serving plates, spoons and cups were displayed to the respondents. The cooked weights were converted to equivalent raw weight $\mathrm{s}$ using the conversion factors. Food consumption table for Bangladesh (Shaheen et al., 2014) was used to estimate the nutrients consumption. The persons consumed during the previous 24-hour were recorded and they were assigned with a man value according to their age and sex. Males above 14 years of age were given a weight of 1.0, females above 11 years and boys from 11 to 14 years of age $0.9,7$ to 10 years children $0.75,4$ to 6 years children 0.4 and less than 4 years children as 0.15 (Jensen et al., 1984). Per capita food and nutrients consumption was obtained by dividing the total consumption with total consumption unit. Then individual intake of reproductive age women were calculated multiplying the per capita consumption by corresponding room scale (0.9). Nutritional adequacy was obtained comparing the individual intake to the recommended intake (RDA, EAR, RNI, AI, UL) (Institute of Medicine, 2006).

\section{Results}

\subsection{Characteristics of the respondents}

Table 1 shows the background information of the respondents. More than half (57.5\%) of the participants were at the ages between 20-34 years and about one-fifth were at their teen ages. More than $80 \%$ of the respondents were found leading their married lives. Mostly were found involved in domestic chores, $14.3 \%$ were students and few were engaged in other activities. Above two-third (69.1\%) were found having formal education between secondary and higher secondary and the left were those having education below primary. About 58\% of the households were found food secured. Almost three-fourth (73.5\%) of the respondents were observed maintaining proper hygiene practices. 
Asian J. Med. Biol. Res. 2020, 6 (4)

Table 1. General characteristics of study participants.

\begin{tabular}{|c|c|}
\hline & $\mathbf{N}(\%)$ \\
\hline \multicolumn{2}{|l|}{ Age in years } \\
\hline $15-19$ & $92(19.4)$ \\
\hline $20-34$ & $273(57.5)$ \\
\hline$\geq 35$ & $110(23.2)$ \\
\hline \multicolumn{2}{|l|}{ Marital status } \\
\hline Married & $386(81.3)$ \\
\hline Unmarried & $89(18.7)$ \\
\hline \multicolumn{2}{|l|}{ Occupation } \\
\hline Household activities & $396(83.4)$ \\
\hline Student & $68(14.3)$ \\
\hline other & $11(2.3)$ \\
\hline \multicolumn{2}{|l|}{ Education level } \\
\hline Primary or below & $146(30.7)$ \\
\hline Secondary or higher & $328(69.1)$ \\
\hline Missing & $1(0.2)$ \\
\hline \multicolumn{2}{|l|}{ Income rank } \\
\hline Lowest $(<15000 \mathrm{tk})$ & $170(35.8)$ \\
\hline Middle (15001-25000tk) & $116(24.4)$ \\
\hline Highest $(>25000$ tk $)$ & $189(39.8)$ \\
\hline \multicolumn{2}{|l|}{ Household food security status } \\
\hline Food secure & $275(57.9)$ \\
\hline Food insecure & $200(42.1)$ \\
\hline \multicolumn{2}{|l|}{ Sanitation facility } \\
\hline Hygienic & $349(73.5)$ \\
\hline Unhygienic & $126(26.5)$ \\
\hline
\end{tabular}

\subsection{Nutritional status of the participants}

The distribution of nutritional status in different socio economic groups is shown on table 2 . About $68 \%$ of the respondents were found either underweight, overweight or obese. Only about 32\% of the participants were found having a normal BMI range. The percentage of underweight, overweight and obesity among the participants were $13.3 \%, 35.8 \%$ and $19.6 \%$ respectively.

Table 2. Nutritional status by different socio demographic characteristics.

\begin{tabular}{|c|c|c|c|c|}
\hline & $\begin{array}{l}\text { Underweight } \\
\%(95 \% \mathrm{CI})\end{array}$ & $\begin{array}{l}\text { Overweight } \\
\%(95 \% \text { CI })\end{array}$ & $\begin{array}{l}\text { Obese } \\
\%(95 \% \mathrm{CI})\end{array}$ & *P value \\
\hline All & $13.3(10.25,16.36)$ & $35.8(31.49,40.12)$ & $19.6(16.04,23.17)$ & \\
\hline \multicolumn{5}{|l|}{ Age in years } \\
\hline $15-19$ & $27.2(18.11,36.3)$ & $17.4(9.66,25.15)$ & $8.7(2.95,14.46)$ & $<0.0001$ \\
\hline $20-34$ & $8.8(5.44,12.17)$ & $40.3(34.49,46.12)$ & $23.8(18.75,28.86)$ & \\
\hline$\geq 35$ & $12.7(6.48,18.93)$ & $40(30.85,49.16)$ & $18.2(10.99,25.42)$ & \\
\hline \multicolumn{5}{|l|}{ Marital status } \\
\hline Married & $11.4(8.22,14.59)$ & $39.1(34.22,43.99)$ & $21.5(17.39,25.62)$ & $<0.0001$ \\
\hline Unmarried & $21.3(12.8,29.81)$ & $21.3(12.8,29.81)$ & $11.2(4.65,17.76)$ & \\
\hline \multicolumn{5}{|l|}{ Occupation } \\
\hline Household activities & $10.4(7.4,13.41)$ & $38.9(34.1,43.71)$ & $21.7(17.65,25.76)$ & $<0.0001$ \\
\hline Student & $30.9(19.92,41.89)$ & $16.2(7.45,24.96)$ & $5.9(0.3,11.51)$ & \\
\hline other & $9.1(-7.9,26.1)$ & $45.5(16.08,74.93)$ & $27.3(0.98,53.64)$ & \\
\hline \multicolumn{5}{|l|}{ Education level } \\
\hline Primary or below & $13(7.55,18.46)$ & $40.4(32.45,48.36)$ & $15.8(9.89,21.72)$ & 0.41 \\
\hline Secondary or higher & $13.1(9.45,16.76)$ & $33.8(28.69,38.92)$ & $21.3(16.87,25.74)$ & \\
\hline \multicolumn{5}{|l|}{ Income rank } \\
\hline Lowest & $17.6(11.88,23.33)$ & $34.7(27.55,41.86)$ & $16.5(10.93,22.08)$ & 0.32 \\
\hline Middle & $13.8(7.53,20.08)$ & $36.2(27.46,44.95)$ & $19(11.87,26.14)$ & \\
\hline Highest & $9(4.92,13.09)$ & $36.5(29.64,43.37)$ & $22.8(16.82,28.79)$ & \\
\hline
\end{tabular}




\begin{tabular}{lllll}
\hline Household food security & & & \\
Food secure & $10.9(7.22,14.59)$ & $37.1(31.4,42.81)$ & $19.6(14.91,24.3)$ & 0.35 \\
Food insecure & $16.5(11.36,21.65)$ & $34(27.44,40.57)$ & $19.5(14.01,25)$ & \\
\hline Family size & & & & \\
４ members & $9(4.16,13.85)$ & $43.3(34.92,51.69)$ & $20.1(13.32,26.89)$ & 0.09 \\
$>4$ members & $15(11.13,18.88)$ & $32.8(27.71,37.9)$ & $19.4(15.11,23.7)$ & \\
\hline Sanitation facility & & & & \\
Hygienic & $12.9(15.26,23.55)$ & $37(31.94,42.07)$ & $18.9(14.8,23.01)$ & 0.81 \\
Unhygienic & $14.3(8.19,20.42)$ & $32.5(24.33,40.68)$ & $21.4(14.24 .28 .57)$ & \\
\hline
\end{tabular}

*p-value from chi-square test

\subsection{Consumption of various food groups}

Per day intake of different food groups is presented on table 3. The median consumption of staple cereal was $500 \mathrm{~g}$ per day. Consumption of fruits and vegetables, meat and fish, milk and dairy products was about $171 \mathrm{~g}$, $134 \mathrm{~g}$ and $141 \mathrm{~g}$ respectively. Total fats and oil intake was about $33.5 \mathrm{~g}$ and sugar and beverages intake was about $53 \mathrm{~g}$.

Table 3. Weight of different food groups consumed by reproductive aged women, in grams per day.

\begin{tabular}{llll}
\hline & Mean (SD) & Median (IQR) & Min-max \\
\hline Cereal & $570.829(340.438)$ & $500.00(312.50-754.70)$ & $28.57-3041.47$ \\
\hline Nuts and legume & $95.462(83.273)$ & $71.429(40.741-114.286)$ & $11.11-500.00$ \\
\hline Roots and tubers & $153.329(119.986)$ & $120.00(67.20-208.950)$ & $7.68-765.47$ \\
\hline Fruits and vegetables & $238.954(235.383)$ & $171.435(91.40-309.315)$ & $8.86-2310.90$ \\
\hline Meat and fish & $201.098(192.817)$ & $134.00(75.00-240.40)$ & $9.00-1360$ \\
\hline Egg & $57.926(42.633)$ & $48.333(34.118-69.979)$ & $2.18-232$ \\
\hline Milk and dairy products & $183.603(132.197)$ & $140.659(87.50-264.285)$ & $6.67-571.43$ \\
\hline Fats and oil & $46.571(39.820)$ & $33.466(17.324-63.833)$ & $2.22-248.00$ \\
\hline Sugar and beverages & $88.337(106.539)$ & $52.778(15.250-124.519)$ & $1.54-719.42$ \\
\hline
\end{tabular}

\subsection{Dietary macronutrients consumption and adequacy}

Table 4 shows dietary energy and macronutrients consumption and their adequacy in comparison to the recommended intake. Although dietary protein consumption was in the recommended range, the median dietary carbohydrate $(65.224 \%)$ and fiber (31g) consumption exceeded the RIR. About one-fourth (25.9\%) of the participants were found to consume protein less than recommended range. Almost all (97.7\%) the respondents consumed carbohydrate above or equal to RIR value. On the other hand, total fat (18.9\%) consumption was below the RIR and more than half (56.8\%) the respondents were found to consume less fat in comparison to RIR.

Table 4. Consumption of energy and macronutrients and their adequacy.

\begin{tabular}{|c|c|c|c|c|c|c|}
\hline & \multicolumn{3}{|c|}{ Intake/ person/day } & \multirow{2}{*}{$\begin{array}{l}\text { Recommended } \\
\text { Intake Range } \\
\text { (RIR) }\end{array}$} & \multicolumn{2}{|c|}{ Percentage with intakes } \\
\hline & Median & $\mathbf{Q}_{25}$ & $\mathbf{Q}_{75}$ & & $\begin{array}{l}\text { Below } \\
\text { RIR }\end{array}$ & $\begin{array}{l}\text { Above/equal to } \\
\text { RIR }\end{array}$ \\
\hline Energy (kcal) & 2827.96 & 1768.08 & 4175.1 & & & \\
\hline Carbohydrate (E\%) & 65.224 & 57.992 & 72.358 & $45-65 \%$ & 2.3 & 97.7 \\
\hline Protein $(\mathrm{E} \%)$ & 11.871 & 9.773 & 15.353 & $10-35 \%$ & 25.9 & 74.1 \\
\hline Total fat $(\mathrm{E} \%)$ & 18.899 & 11.840 & 26.556 & $20-35 \%$ & 56.8 & 43.2 \\
\hline Dietary fiber (g/day) & 31.057 & 18.172 & 45.138 & $25 \mathrm{~g} /$ day & 40.0 & 60.0 \\
\hline
\end{tabular}

$\%$ E: percentage of total energy intake

\subsection{Dietary micronutrients consumption and adequacy}

Table 5 describes the dietary intake of various micronutrients along with their adequacy compared to recommended intake. Median consumption of vitamin A, D, Folic acid, calcium, sodium, potassium was very poor and found below EAR/AI among the most respondents. About half of the participants consumed vitamin $\mathrm{C}$ and riboflavin below EAR/AI. On the other hand, niacin and magnesium consumption was found exceeding the UL in about $60 \%$ respondents. 
Table 5. Consumption of micronutrients and their adequacy.

\begin{tabular}{|c|c|c|c|c|c|c|}
\hline & \multicolumn{3}{|c|}{ Intake/ person/day } & & \multicolumn{2}{|c|}{ Percentage with intakes } \\
\hline & Median & $\mathrm{Q}_{25}$ & $\mathrm{Q}_{75}$ & EAR/AI & Below EAR/AI & Above UL \\
\hline Vitamin A ( $\mu \mathrm{g} /$ day $)$ & 98.658 & 42.397 & 233.266 & $500 \mu \mathrm{g} /$ day & 87.6 & - \\
\hline Vitamin C (mg/day) & 64.301 & 35.166 & 119.457 & $60 \mathrm{mg} /$ day & 46.9 & - \\
\hline Vitamin D $(\mu \mathrm{g} /$ day $)$ & 0.7667 & 0.0013 & 3.156 & $10 \mu \mathrm{g} /$ day & 99.2 & - \\
\hline Thiamin (mg/day) & 1.898 & 1.156 & 2.795 & $0.9 \mathrm{mg} /$ day & 12.0 & - \\
\hline Riboflavin (mg/day) & 0.910 & 0.605 & 1.418 & $0.9 \mathrm{mg} / \mathrm{day}$ & 49.5 & - \\
\hline Niacin (mg/day) & 41.998 & 23.899 & 61.227 & $11 \mathrm{mg} / \mathrm{day}$ & 1.3 & 60.4 \\
\hline Folic acid ( $\mu \mathrm{g} /$ day $)$ & 187.251 & 126.314 & 301.680 & $320 \mu \mathrm{g} /$ day & 77.9 & 0.2 \\
\hline Iron (mg/day) & 11.626 & 7.498 & 16.837 & $8.1 \mathrm{mg} /$ day & 28.0 & 2.1 \\
\hline Zinc ( mg/day) & 13.841 & 8.370 & 20.083 & $6.8 \mathrm{mg} /$ day & 14.9 & 4.2 \\
\hline Calcium (mg/day) & 258.420 & 143.373 & 644.136 & $800 \mathrm{mg} /$ day & 78.9 & 5.7 \\
\hline Phosphorous (mg/day) & 1312.839 & 829.287 & 1893.071 & $580 \mathrm{mg} /$ day & 8.2 & 4.2 \\
\hline Sodium (mg/day) & 267.990 & 148.085 & 611.571 & $1500 \mathrm{mg} /$ day & 94.1 & 1.9 \\
\hline Potassium (mg/day) & 2407.311 & 1467.63 & 3618.138 & $4700 \mathrm{mg} /$ day & 88.4 & - \\
\hline Magnesium (mg/day) & 420.948 & 272.028 & 625.568 & $255 \mathrm{mg} /$ day & 20.6 & 62.7 \\
\hline
\end{tabular}

\section{Discussion}

This paper reveals the nutritional status of the reproductive aged women, their dietary food and nutrients intake patterns and adequacy of dietary energy and nutrients in comparison to the recommended intake. In our study, we found only about $32 \%$ respondents at their normal BMI cut off points which is lower than the percentage of Bangladesh Demographic and Health Survey 2014 (Statistics Bureau and Mitra Associates, 2013). The percentage of underweight in our study was $13.3 \%$, lower than the percentage in Bangladesh Demographic and Health Survey 2014. Overweight and obesity have been increased in Bangladesh during the last decades and we also found so. The chi-square test shows that age, marital status and occupation of the respondents are significantly associated with their nutritional status. Though underweight was prevalent among the teen agers, over weight and obesity were higher among the adults. Prevalence of underweight was higher among the unmarried and overweight and obesity were higher among the married. Percentage of underweight was higher and overweight, obesity were lower among the students. Although educational level, income rank, food security, family size, sanitation facility were not significantly associated, the percentage of overweight and obesity was higher among the highest income group, food secured families, families with low member.

Dietary information found in this study showed that the consumption of cereal, nuts and legume, roots and tubers, fruits and vegetables, meat and fish, egg, milk and dairy products, fats and oil, sugar and beverages have increased as compared to that of from the national surveys (NIPORT and Mitra Associates, 2016). Dietary energy, carbohydrate, protein, fat, fiber consumption have increased over the years.

Although dietary protein consumption was in the recommended range, about one-fourth (25.9\%) of the respondents were found to consume protein below the lower boundary of the recommended intake range. Carbohydrate intake met the recommended value and mostly exceed the upper boundary of recommended intake range. Total fat (18.9\% of the total energy) consumption was below the RIR and more than half (56.8\%) of the respondents were found to consume less fat in comparison to their RIR. Dietary fiber consumption was higher than the recommended value but still $40 \%$ of the participants were found to consume less dietary fiber compared to the recommended value. In case of the micronutrients, dietary consumption of several vitamins like vitamin $\mathrm{A}$, vitamin D, Folic acid was very poor among the most respondents. Although median vitamin $\mathrm{C}$ and riboflavin consumption was higher than the RIR value, about half of the participants were found to consume below EAR/AI. In case of minerals, the consumption of calcium, sodium, potassium was very poor as compared to the requirements. Thiamin, zinc, iron, phosphorous intake was satisfactory among the most respondents. On the other hand, niacin and magnesium consumption was higher than the recommended value and was found exceeding the UL in about $60 \%$ respondents.

\section{Limitation of the study}

As 24-hour recall dietary data were collected, actual weight of food consumed was not found and the weight was adjusted by approximation. Because individual intake was not taken, the intake obtained from the household consumption might deviate from their actual intake. 


\section{Conclusions}

The prevalence of underweight and normal nutritional status among reproductive aged women were lower than the prevalence in national prevalence. But the prevalence of overweight and obesity was increased over the years. Age, marital status and occupation of the respondents were significantly associated with their nutritional status. Dietary intake of various food groups increased as compared to national surveys. Dietary energy, protein, fats and oils intake also increased. Adequacy of dietary energy, carbohydrate and protein consumption was satisfactory but still fats and oil consumption was very low compared to their requirements. Consumption of vitamin A, D, Folic acid, vitamin C, riboflavin, calcium, sodium, potassium was unsatisfactory, below EAR/AI among the most respondents but niacin and magnesium consumption was found exceeding the UL. Thiamin, zinc, iron, phosphorous consumption was found satisfactory among most of the respondents. Therefore, priority should be given on their nutritional status and improved diet in terms of quality and quantity. I

\section{Acknowledgments}

We would like to thank Professor Dr. Md. Nazrul Islam Khan and Hon's final year students (19th batch) of Institute of Nutrition and Food Science, University of Dhaka for their support and cooperation on this study and the authority of Bangladesh Academy for Rural Development (BARD), Cumilla.

\section{Conflict of interest}

None to declare.

\section{References}

Ahmed F, N Prendiville and A Narayan, 2016. Micronutrient deficiencies among children and women in Bangladesh: progress and challenges. J. Nutri. Sci., 5: 112.

Biswas T, MJ Uddin, AA Mamun, S Pervin, and P Garnett S 2017. Increasing prevalence of overweight and obesity in Bangladeshi women of reproductive age: Findings from 2004 to 2014. Plos one, 12: e0181080.

Bmi, WHO and TWHO Bmi, 2004. Public health Appropriate body-mass index for Asian populations and its implications for policy and intervention strategies', 363, pp. 157-163.

Chopra SM, A Misra, S Gulati and R Gupta, 2013. Overweight, obesity and related non-communicable diseases in Asian Indian girls and women. European J. Clin. Nutri., 67: 688-696.

Drewnowski A and BM Popkin, 2009. The Nutrition Transition: New Trends in the Global Diet. Nutri. Rev., 55: 31-43.

Institute of Medicine, 2006. Dietary Reference Intakes: the essential guide to nutrient requirements, Dietary Reference Intakes: the essential guide to nutrient requirements. doi: 10.17226/11537.

Jensen, OM, J Wahrendorf, A Rosenqvist and A Geser, 1984. The reliability of questionnaire-derived historical dietary information and temporal stability of food habits in individuals. American J. Epidemiol., 120: 281290.

Kaiser LL and L Allen, 2002. Position of The American Dietetic Association. J. American Diet. Asso., 102: $1479-1490$.

Mamun AA, LK Callaway, MJ O'Callaghan, GM Williams, JM Najman, R Alati, A Clavarino, DA Lawlor, 2011. Associations of maternal pre-pregnancy obesity and excess pregnancy weight gains with adverse pregnancy outcomes and length of hospital stay. BMC Preg. Child., 11: 1-9.

Miranda JJ, Kinra S, Casas JP, Davey Smith G and S Ebrahim, 2008. Non-communicable diseases in low- and middle-income countries: context, determinants and health policy. Trop. Med. Int. Heal., 13: 1225-1234.

Shaheen N, ATMA Rahim, M Mohiduzzaman, CP Banu, ML Bari, AB Tukun, MA Mannan, LBS Bhattacharjee, 2014. Food composition table for Bangladesh, Igarss 2014.

Nguyen PH, L Huybregts, TG Sanghvi, LM Tran, EA Frongillo, P Menon and MT Ruel, 2018. Dietary Diversity Predicts the Adequacy of Micronutrient Intake in Pregnant Adolescent Girls and Women in Bangladesh, but Use of the 5-Group Cutoff Poorly Identifies Individuals with Inadequate Intake. J. Nutri., 148: 790-797.

Nie N, D Bent and C Hull, 1975. SPSS: Statistical package for the social sciences.

NIPORT and Mitra Associates, 2016. Household Income and Expenditure Survey, Bangladesh 2016'.

Sebire N, M Jolly, J Harris, L Regan and S Robinson, 2001. Is maternal underweight really a risk factor for adverse pregnancy outcome? A population-based study in London. British J. Obst. Gynaecol., 108: 61-66.

Shafique S, N Akhter, G Stallkamp, S de Pee, D Panagides, and MW Bloem, 2007. Trends of under- and overweight among rural and urban poor women indicate the double burden of malnutrition in Bangladesh. Int. J. Epidemiol., 36: 449-457. 
Simpson JL, LB Bailey, K Pietrzik, B Shane and W Holzgreve, 2010. Micronutrients and women of reproductive potential: required dietary intake and consequences of dietary deficiency or excess. Part I Folate, Vitamin B12, Vitamin B6. J. Mat. Fet. Neon. Med., 23: 1323-1343.

Simpson JL, LB Bailey, K Pietrzik, B Shane and W Holzgreve, 2010. Micronutrients and women of reproductive potential: required dietary intake and consequences of dietary deficienty or excess. Part II Vitamin D, Vitamin A, Iron, Zinc, Iodine, Essential Fatty Acids. J. Mat. Fet. Neon. Med., 24: 1-24.

Statistics Bureau and Mitra Associates, 2013. Bangladesh Demographic and Health survey 2014, NIPORT, Mitra and Associates, and ICF International. 